\title{
The Ambient from the Young Passengers' Perception in the Carriage of Taiwan High Speed Rail
}

\author{
Jeichen Hsieh and Chan Yo Shan \\ Tung Hai University, Dept. of Industrial Design, Taiwan \\ jeichen@thu.edu.tw, ruby1986311@yahoo.com.tw
}

To explore the Taiwan High Speed Rail passenger experience of environmental attitudes, the concept car as a potential environmental factors (Table 1) to Hershberg \& Cass environmental significance of the semantic scale (Table 2) (Xu Leiqing, 2004) as Measurement tools of environmental factors in the compartment of the bipolar adjective semantic differential method is usually the number must be used about 10 to 30 is more suitable, it will be adjusted to 2 to 3 group to obtain more stable reference. Online questionnaire with Taiwan High Speed Rail train running video will be a reference tool to assist measurement. The video contents directly play to compare the experience feedback of fifty passengers.

Table 1. Potential environmental of high-speed rail travel

\begin{tabular}{|l|}
\hline Potential environmental factors \\
\hline Passenger vehicles 乘客 \\
\hline $\begin{array}{l}\text { Changes in acceleration and } \\
\text { deceleration }\end{array}$ \\
\hline Stationary traffic \\
\hline Speed \\
\hline Air Quality \\
\hline Temperature and humidity \\
\hline Path \\
\hline Noise \\
\hline Light \\
\hline Seating range \\
\hline Color \\
\hline
\end{tabular}


Table 2. Scale selection

\begin{tabular}{|lll|}
\hline Concept & Main scale & Alternative scale \\
Overall rating & good - the bad & pleasant - unpleasant \\
Evaluate the effectiveness & of useful - useless & friendly - hostile \\
Evaluation of the unique aesthetic & unique - plain & interesting - boring \\
Activities & positive - negative & complex - simple \\
Space & small - spacious & private - public \\
Effect & ugly - fine & rough - smooth \\
Neat and clean & clean - dirty & well organized - messy \\
Organization & casual - mess & formal - free \\
Temperatures & warm - cold & hot - cool \\
Bright & light - dark & cheerful - boring \\
\hline
\end{tabular}

\section{The Carriage and Use of Environmental Objects}

According to the Taiwan High Speed Rail High Speed Rail website Inside information on the object for investigation of high-speed rail passengers traveling within the scope of physical activity when environmental objects, finishing as the standard range of cars and commercial cars (Table 2.3), does not contain a barrier-free space, toilets, vending machines, public telephones. Environment provides an object inside a passenger seat on the journey to provide the needs of Taiwan High Speed Rail interior finishing environmental objects such as table 3.

Research show that although many high-speed rail seat space to facilitate the design and intimate personal use universal design considerations, there are still inadequacies in the actual use of passengers when the environment was due to restrictions that could result in the occurrence of passenger interference between the activities , are summarized as follows:

1. Table design in the seat behind the current seat back angle adjustment, back seat passengers to use the table immediately affected, and the appropriate table can not be smoothly adjusted.

2. For standard car seats configured as $3+2$, crowded, passengers will feel sitting in the middle than the narrow space available.

3. Standard Cabin narrow the distance between each seat, so passengers to use the table, almost the desktop can be temporary seat at a glance.

4. Seat can be rotated 180 degrees relative to facilitate understanding of the passengers sit, also happens to be equal to all the people are no table can be used. 
Table 3. Environmental Investigation

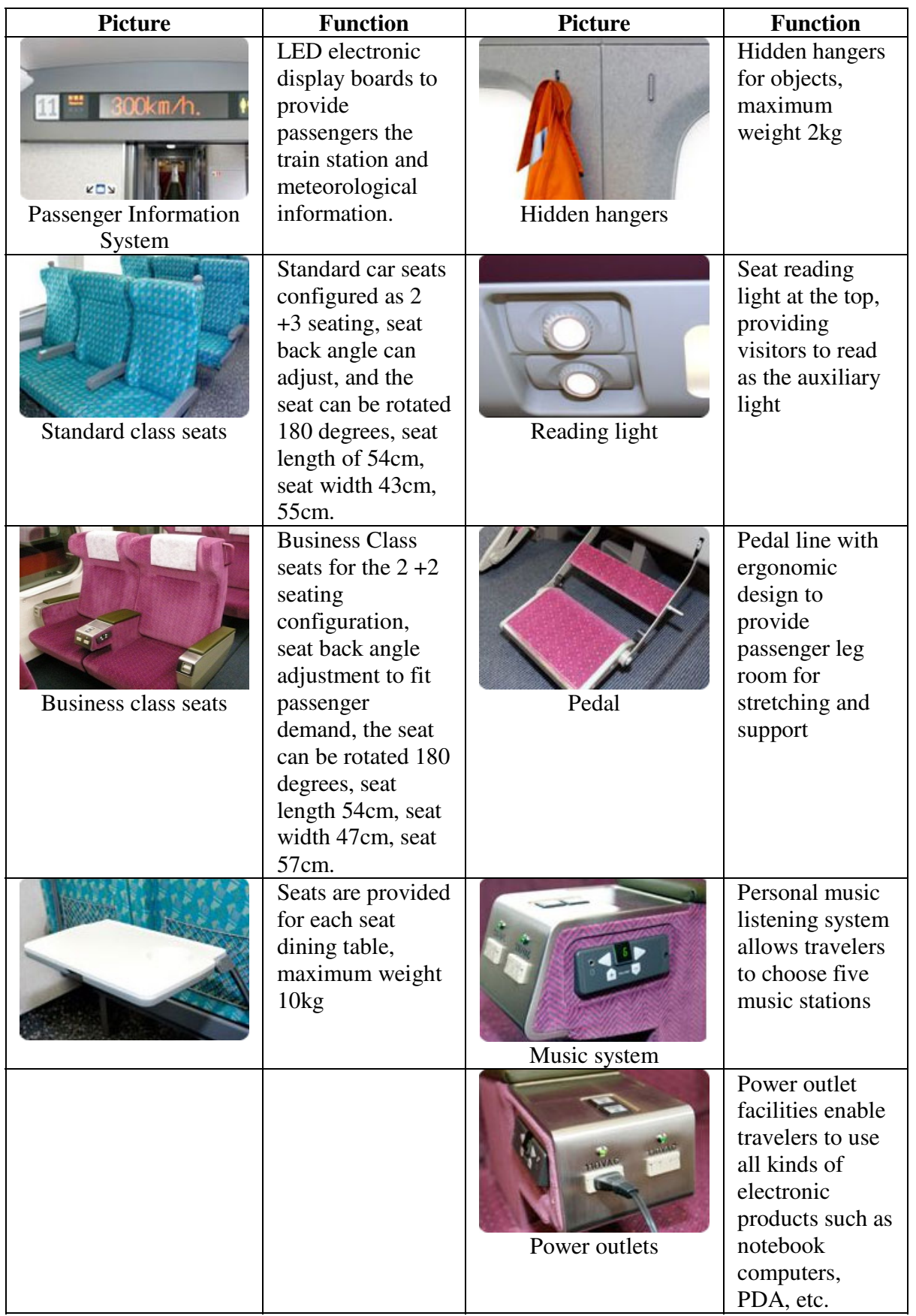

Note: From the Taiwan High Speed Rail, http://www.thsrc.com.tw 